\title{
Infantile spongy degeneration of the central nervous system associated with glycogen storage and markedly fatty liver ${ }^{1}$
}

\author{
Y. TAKEI AND G. B. SOLITARE \\ From the Department of Pathology (Neuropathology) \\ Yale University School of Medicine, New Haven, Conn., U.S.A.
}

SUMMARY The clinical, biochemical, and pathological features of an unusual expression of infantile spongy degeneration of the central white matter are presented with emphasis on neuropathological observations. The topographical distribution of the spongy change along with the observed defect in myelination were such as to suggest an arrest in development of the white matter in late foetal life. Of additional interest, in the present case, is the observed deposition of glycogen in the brain, heart, and liver along with a markedly fatty liver. Our findings are compared with those in other cases of so-called spongy degeneration, as well as with certain of the aminoacidurias and, as a consequence, we wish to suggest that the basic pathogenetic factor probably lies in a disturbance of the biochemical energy supply system rather than in a disorder of myelin lipid metabolism per se.

While 'spongy degeneration' has been considered as an expression of a specific clinicopathological entity-that is, van BogaertBertrand type of spongy degeneration (B-BSD) or Canavan's disease (van Bogaert and Bertrand, 1967)-so-called status spongiosus of the brain has been observed in a variety of neurological disorders (Seitelberger, 1967). In particular, diffuse spongy change of the central white matter quite similar to that of B-BSD has been reported as a characteristic neuropathological feature in infantile cases of several metabolic disorders, notably those of the genetic aminoacidurias-for example, phenylketonuria (Alvord, Stevenson, Vogel, and Engle, 1950), maple syrup urine disease (Silberman, Dancis, and Feigin, 1961), and others (Chou and Waisman, 1965; Donohue, 1967; Rushton, 1968; Solitare, Shih, Nelligan, and Dolan, 1969).

According to Seitelberger (1967), the conditions referred to by the term 'spongy degeneration' are consistent with 'dystrophies of the cerebral transport structures', since the pathogenesis of such spongy change supposedly is closely related to disorders of cerebral transport mechanisms. Recently, Jellinger and Seitelberger

1 Supported in part by NINDS grant NSO6882 of the United Public Health Service.
(1970) presented a thorough review of this complicated neuropathological problem.

The purpose of this report is to describe another example of infantile spongy degeneration of the central white matter, in this instance associated with abnormal glycogen deposition in the brain, liver and heart, and with a markedly fatty liver.

\section{CASE REPORT}

CLINICAL FINDINGS A 4 month old Japanese girl was admitted to the hospital because of retarded physical development. The child was the first born of healthy parents, who were consanguineous (first cousins). She was born at full term, spontaneously, after an uneventful gestation, weighing $3,250 \mathrm{~g}$ at birth.

Soon after birth, the child developed episodes of vomiting associated with intermittent low grade fevers. These persisted and at 4 months of age she still had poor head control, a weak cry, and floppy extremities.

Physical examination on admission revealed a poorly nourished infant girl whose face was puffy and pale with an apathetic expression, not unlike that of a doll. The conjunctivae were pale, but nonicteric. The skin was not jaundiced, but was dry with poor turgor. No abnormalities of the heart or lungs were detected. The abdomen was distended, but no 
ascites was noted. The abdominal veins were slightly engorged. The liver was palpated $7 \mathrm{~cm}$ below the right costal margin in the mid-clavicular line, having a smooth non-tender surface with sharp edges. The spleen was not palpable. The extremities were thin and hypotonic. No patellar or ankle reflexes were elicited. No pathological reflexes were present.

Laboratory studies showed a fasting hypoglycaemia with poor response to adrenaline stimula-

TABLE 1

LABORATORY FINDINGS

\begin{tabular}{|c|c|c|c|c|}
\hline & \multicolumn{4}{|c|}{ Age (months) } \\
\hline & 4 & 7 & 9 & 11 \\
\hline $\begin{array}{l}\text { Blood and serum } \\
\text { RBC }\left(\times 10^{4} / \mathrm{mm}^{3}\right) \\
\text { Hb }(\mathrm{g} / \mathrm{dl}) \\
\text { Ht }(\%) \\
\text { WBC }\left(/ \mathrm{mm}^{3}\right) \\
\text { Blood sugar }(\mathrm{mg} / \mathrm{dl}) \\
\text { Cholesterol }(\mathrm{mg} / \mathrm{dl}) \\
\text { free } \\
\text { ester } \\
\text { Total lipid }(\mathrm{mg} / \mathrm{di}) \\
\text { Total protein }(\mathrm{g} / \mathrm{dl}) \\
\text { albumin } \\
\alpha-\text { globulin } \\
\beta-\text { globulin } \\
\gamma-\text { globulin } \\
\text { A/G } \\
\text { K (m-equiv } / 1 .) \\
\mathrm{Na}(\mathrm{m} \text {-equiv } / 1 .) \\
\mathrm{Cl}(\mathrm{m} \text {-equiv } / \mathrm{l} .) \\
\text { Ca (m-equiv } / 1 .) \\
\text { P (m-equiv } / 1 .)\end{array}$ & $\begin{array}{c}4.6 \\
2.83 \\
0.40 \\
0.48 \\
0.98 \\
1.5 \\
5.90 \\
139.4 \\
97.0 \\
3.84 \\
6.36\end{array}$ & $\begin{array}{c}269 \\
7 \cdot 2 \\
26 \\
11750 \\
68 \cdot 0 \\
380 \\
226 \\
154\end{array}$ & $\begin{array}{c}400 \\
9.7 \\
36 \\
24600 \\
40.0 \\
375 \\
208 \\
167 \\
860 \\
6.6 \\
3.42 \\
0.94 \\
1.06 \\
1.18 \\
1.07 \\
6.00 \\
134.0 \\
98.5 \\
4.60 \\
5.50\end{array}$ & $\begin{array}{c}427 \\
12 \cdot 7 \\
45 \\
25500 \\
\\
675 \\
470 \\
205\end{array}$ \\
\hline $\begin{array}{l}\text { Protein } \\
\text { Sugar } \\
\text { Urobilinogen } \\
\text { Bilirubin } \\
\text { Acetone }\end{array}$ & $\begin{array}{l}- \\
\pm \\
\overline{-}\end{array}$ & $\begin{array}{l}- \\
+ \\
+ \\
+ \\
+\end{array}$ & $\begin{array}{l}- \\
- \\
+ \\
+\end{array}$ & $\begin{array}{l} \pm \\
\pm \\
\pm \\
\pm\end{array}$ \\
\hline $\begin{array}{l}\text { Urine } \\
\text { 17-KS (mg/day) } \\
\text { 17-OHCS (mg/day) } \\
\text { Tetrahydrocortisol } \\
\text { Tetrahydrocortisone } \\
\text { Cortisol } \\
\text { Cortisone } \\
\text { Corticosterone }\end{array}$ & $\begin{array}{l}\text { ( } \gamma / \text { day }) \\
\text { ( } \gamma / \text { day }) \\
\text { ( } \gamma / \text { day }) \\
\text { ( } \gamma / \text { day }) \\
\text { ( } \gamma / \text { day })\end{array}$ & $\begin{array}{l}3.08 \\
0.06\end{array}$ & $\begin{array}{c}2 \cdot 16 \\
0 \cdot 10 \\
68 \cdot 8 \\
16 \cdot 2 \\
9 \cdot 6 \\
5 \cdot 6 \\
6 \cdot 4\end{array}$ & \\
\hline $\begin{array}{l}\text { Pyruvic acid (mg/dl) } \\
\alpha \text {-ketoglutaric acid (mg/ }\end{array}$ & & & & $\begin{array}{r}24 \cdot 0 \\
120 \cdot 0\end{array}$ \\
\hline $\begin{array}{l}\text { Liver function } \\
\text { SGOP } \\
\text { SGPT } \\
\text { TTT } \\
\text { CCF }\end{array}$ & $\begin{array}{l}63 \\
45 \\
1 \cdot 2\end{array}$ & $\begin{array}{c}144 \\
72 \\
9 \cdot 1 \\
+++\end{array}$ & $\begin{array}{c}131 \\
82 \\
1 \cdot 7 \\
+\end{array}$ & \\
\hline $\begin{array}{l}\text { Alkaline phosphatase (B } \\
\text { Bilirubin total (mg/dl) } \\
\text { direct } \\
\text { indirect }\end{array}$ & U) & $\begin{array}{l}4 \cdot 6 \\
2 \cdot 7 \\
1 \cdot 9\end{array}$ & $\begin{array}{l}6 \cdot 65 \\
5 \cdot 4 \\
3 \cdot 1 \\
2 \cdot 3\end{array}$ & $\begin{array}{l}4 \cdot 00 \\
3 \cdot 4 \\
1 \cdot 5 \\
1 \cdot 9\end{array}$ \\
\hline \multicolumn{2}{|c|}{$\begin{array}{l}\text { Diastase in urine (WGU) } \\
\text { Trypsin in faeces }\end{array}$} & \multicolumn{3}{|c|}{$\begin{array}{c}25 \\
400 \times\end{array}$} \\
\hline $\begin{array}{l}1131 \text { uptake } \\
30 \mathrm{~min} \\
24 \mathrm{hr}\end{array}$ & & $\begin{array}{l}28 \cdot 1 \% \\
18 \cdot 1 \%\end{array}$ & & \\
\hline $\begin{array}{l}\text { Aldolase in erythrocyte } \\
\text { G6PD in erythrocyte }(u)\end{array}$ & $\begin{array}{l}\text { l/ml.) } \\
\text { nl.) }\end{array}$ & & $\begin{array}{r}816 \\
2400\end{array}$ & \\
\hline
\end{tabular}

tion. Liver function tests were only slightly abnormal The serum protein level was low and the haemo globin level was $3.2 \mathrm{~g} / 100 \mathrm{ml}$. (Table 1).

A clinical diagnosis of von Gierke's diseas (glycogenosis type I) was considered. A liver biopsyc? performed at the age of 5 months revealed a marke $\bar{P}$ accumulation of fat in the hepatic cells with a minit mal amount of glycogen present. The nutritionah condition of the patient was improved by forced. feedings with a well-balanced diet. The anaemia an hypoproteinaemia soon improved. The body weight: increased from $5.41 \mathrm{~kg}$ to $7.56 \mathrm{~kg}$ in three months Another liver biopsy was taken at the age of 8 months, which showed changes similar to those of the first biopsy - that is, fatty liver-except that mild degree of portal fibrosis was noted.

Based on the clinical features, laboratory data, and the results of the liver biopsies, the diagnosis of congenital hypertrophic steatosis of the liver was made.

At the age of 9 months, an exploratory laparotoms with an open liver biopsy was done. Biochemica analysis of this tissue was performed (for details, see Tada, Katsushima, Hirono, and Arakawa, 1962) The pertinent findings were as follows: (1) The con:tent of fat and cholesterol of the liver was remarka higher than that of normal controls. The glycogers content was not higher in weight percentage of liver, but, on a protein basis, it was higher than normal controls. The glycogen isolated from the specimen had no structural abnormality. (2) क्षे specific activity of glucose-6-phosphatase (G6Pase) was decreased, while that of glucose-6-phosphateo dehydrogenase (G6PDase) was considerably highe N than that of normal controls. The activity of lactic dehydrogenase was slightly elevated, while that of aldolase, phosphoglucomutase, and phosphorylases were all within normal limits. (3) Lipogenesis from glucose was highly activated. Glycolysis was also activated, whereas glycogenesis was at normal level

Histological and histochemical examination of this liver specimen revealed advanced fatty changewith a moderate amount of glycogen around the portal zones, which was considered to be increased. over the amount seen in the previous biopsies.

Physical and mental development proceeded buf very slowly until the age of 10 months. Neck contro $B$ was achieved at 8 months of age. The child would smile when played with and would grab a presenteof object. At 10 months of age, she developed frequen $\hat{b}$ episodes of vomiting as the subcutaneous fat in creased and her skin became jaundiced. She spike frequent fevers associated with leukocytosis and. pyuria. The extremities became increasingly hypo $N$ tonic. At 11 months of age, the child continued tă deteriorate, developing rigidity and trismus. Finally: she became comatose and died at the age of 120 months and 7 days. 


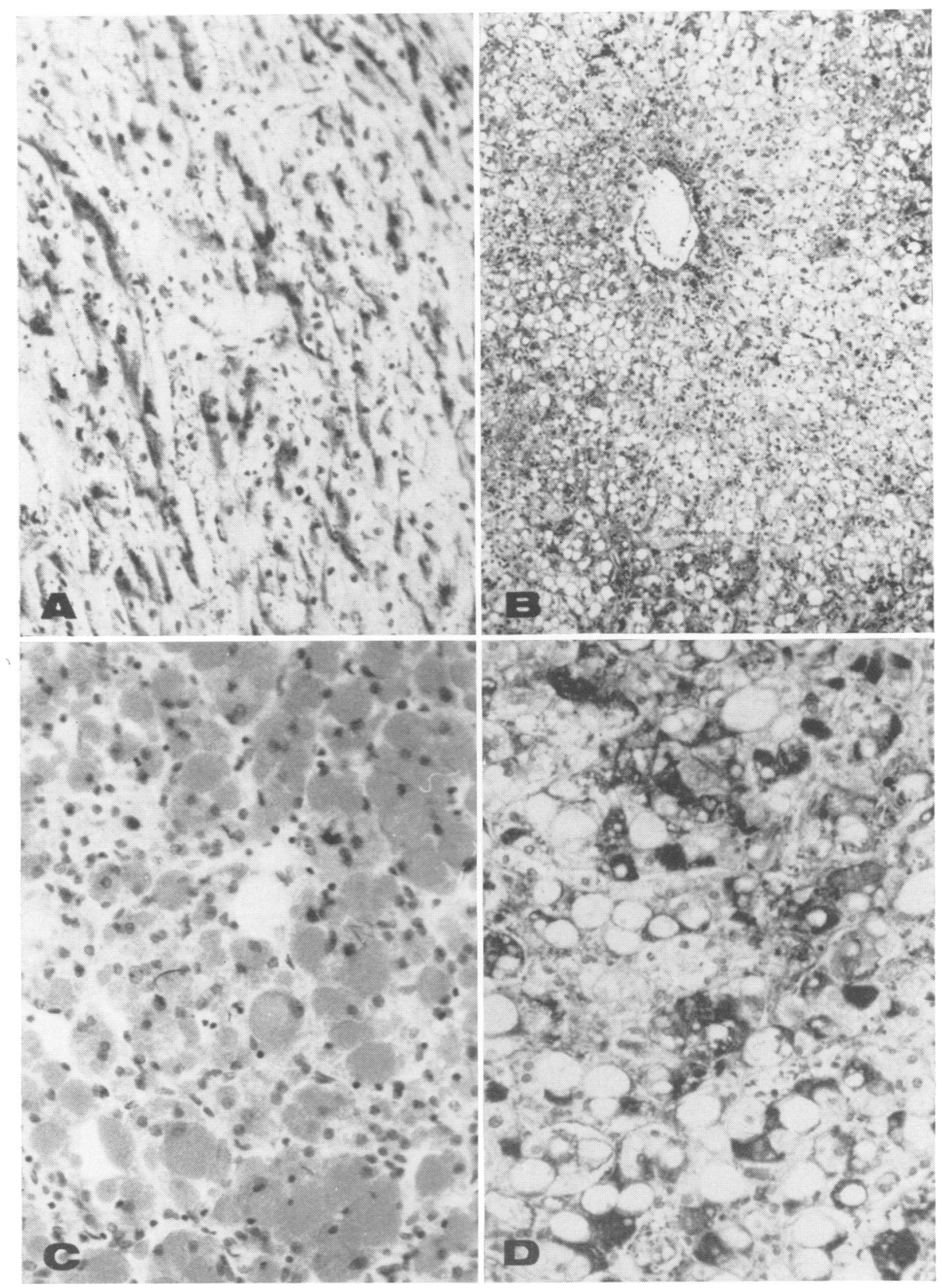

FIG. 1. Changes in the visceral organs. A. Abnormal deposition of glycogen in the myocardium. Best's carmine, paraffin section, $\times 250$. B. General histological appearance of the liver. Masson's trichrome, paraffin section, $\times 70$. C. Marked fatty change in the liver. Sudan IV, frozen section, $\times 300$. D. Glycogen deposition in the hepatic cells. Best's carmine, paraffin section, $\times 250$. 
POST-MORTEM EXAMINATION A necropsy was begun three hours after death. The body was obese and the abdomen was markedly distended with an enlarged liver. The skin was moderately icteric and the subcutaneous fat was abundant.

Death was attributed to the presence of aspirated vomitus in the bronchial tree; no pneumonia was found.

The heart was not enlarged and appeared grossly normal except for slight left ventricular dilatation. While no histological abnormalities were noted, PAS and Best's carmine stains disclosed a large amount of glycogen within the myocardial fibres (Fig. 1A). No sudanophilic material was detected.

The entire gastrointestinal tract was intact except for multiple small, superficial, haemorrhagic ulcerations of the gastric mucosa. Both kidneys showed small multifocal scarring, which was attributed to chronic pyelonephritis. No glycogen or fat storage was in evidence.

The liver was enlarged, weighing $690 \mathrm{~g}$. The cut surface was yellow and greasy with a moderately firm consistency. No abnormalities of the extrahepatic biliary tree were noted. The histological picture was one of marked fatty change with especial involvement of the portal zones with an associated portal fibrosis (Fig. 1B,C). A moderate amount of glycogen was detected in a similar distribution (Fig. 1D). Bile stasis of a moderate degree, most prominent in the pericentral zones, also was seen.

No abnormalities of the spleen were detected. In particular, there was no evidence of fat or glycogen storage. Similarly, no abnormal storage products were found in several samples of skeletal muscle studied.

No microscopic lesions were seen in the endocrine glands.

NEUROPATHOLOGICAL OBSERVATIONS The brain weighed $820 \mathrm{~g}$ immediately after removal. After fixation in $10 \%$ formalin the brain was further examined. No abnormalities were noted in the leptomeninges or over the surfaces of the brain. Multiple coronal sections revealed the cerebral white matter to be diffusely swollen and soft with a greytan gelatinous appearance. The cerebral cortex was uniformly thin throughout and the junction between grey and white matter was indistinct. The contours of the basal grey masses also were indistinct. In the cerebellum, the folia were well formed, but here also the white matter was soft and gelatinous, though less extensively so than that of the centrum semiovale. A similar appearance of the white matter was observed throughout the brain-stem and spinal cord. The spinal roots and cauda equina as well as the peripheral nerves appeared intact.

Representative sections were removed, embedded in paraffin, sectioned at $6 \mu$ and stained with haematoxylin-eosin, Nissl, Klüver-Barrera, Bodian, Woelke, PAS, and Best's carmine techniques. Frozen sections were also cut and stained with $\mathbb{D}$ Sugamo method for myelin, Sudan IV, Sudan Black ō B, Nile Blue Sulphate, and Toluidine Blue.

The cortical neurones were all shrunken witho scanty eosinophilic cytoplasm and hyperchromatic, $\mathcal{D}$ or, at times, vesicular nuclei. Mixed with them were numerous hypertrophic astrocytes, many of which $\frac{\overline{0}}{0}$ could be classified as those of Alzheimer type II, having clear, naked nuclei (Fig. 2). Because of these changes, the normal laminar cytoarchitecture was, in general, obscured except for the superficial layers. 0 In the deeper layers of the cortex, there was a severe $\frac{}{0}$ status spongiosus, apparently in direct continuity $\frac{\bar{c}}{\vec{m}}$ with identical changes in the subjacent white matter. $\vec{\nabla}$ The neurones in these regions were apparently diminished in number. In the hippocampus, how- ${ }^{\circ}$ ever, the pyramidal neurones of the Ammon's horn $\vec{\circ}$ configuration were well preserved together with the $\vec{\overrightarrow{ }}$ small neurones of the fascia dentata. But here also $\stackrel{\omega}{\sigma}$ numerous Alzheimer type II astrocytes were found.

The cerebral white matter revealed an extensive status spongiosus involving uniformly the entire centrum semiovale, extending into the deeper cortex across the subcortical U-fibres (Fig. 2). This spongy change was characterized by severe rarefaction of 0 the affected tissue with numerous, evenly distributef, tiny empty spaces, separated by pale poorly myelifi ated white matter whose cellular population was $\mathbb{D}$ greatly diminished. Normal-appearing oligode droglia were rare. The remaining cells were most astrocytes with many Alzheimer type II forms, bet $\vec{\varphi}$ they were not as numerous as in the cerebral corte The white matter was extremely pale indicating absence of normal myelin structure. This change was not uniform as the deeper portions were slightly better stained, which was better demonstrated with thicker sections. Under high magnification, the white matter was composed of a loosely arranged $\stackrel{\unrhd}{\unrhd}$ mesh-work of myelinated fibres whose pallor $\vec{\overrightarrow{ }}$ reflected their decreased density. The remaining $\frac{}{3}$ myelinated fibres were undergoing variable degrees of $\supset$ regressive change with ballooning, moniliform swell-? ing, etc. (Fig. 3A,B). The axonal population was markedly diminished, but those that remained appeared intact except for occasional kinking and swelling (Fig. 3B,C). A loosely arranged, delicate 3 . fibrous network of hypertrophic fibrillary astrocytes was found throughout the regions of spongy change. No abnormal material could be demonstrated within 0 the empty spaces of the spongy structure. Some accumulation of sudanophilic material (fat) was $\frac{D}{0}$ observed, but very rarely and only around the small vessels.

Although the entire cerebral white matter was $N$ involved with the above described spongy change, N the lenticulothalamic sector of the internal capsule ${ }_{\sigma}^{\omega}$ was the part within the cerebrum least severely 


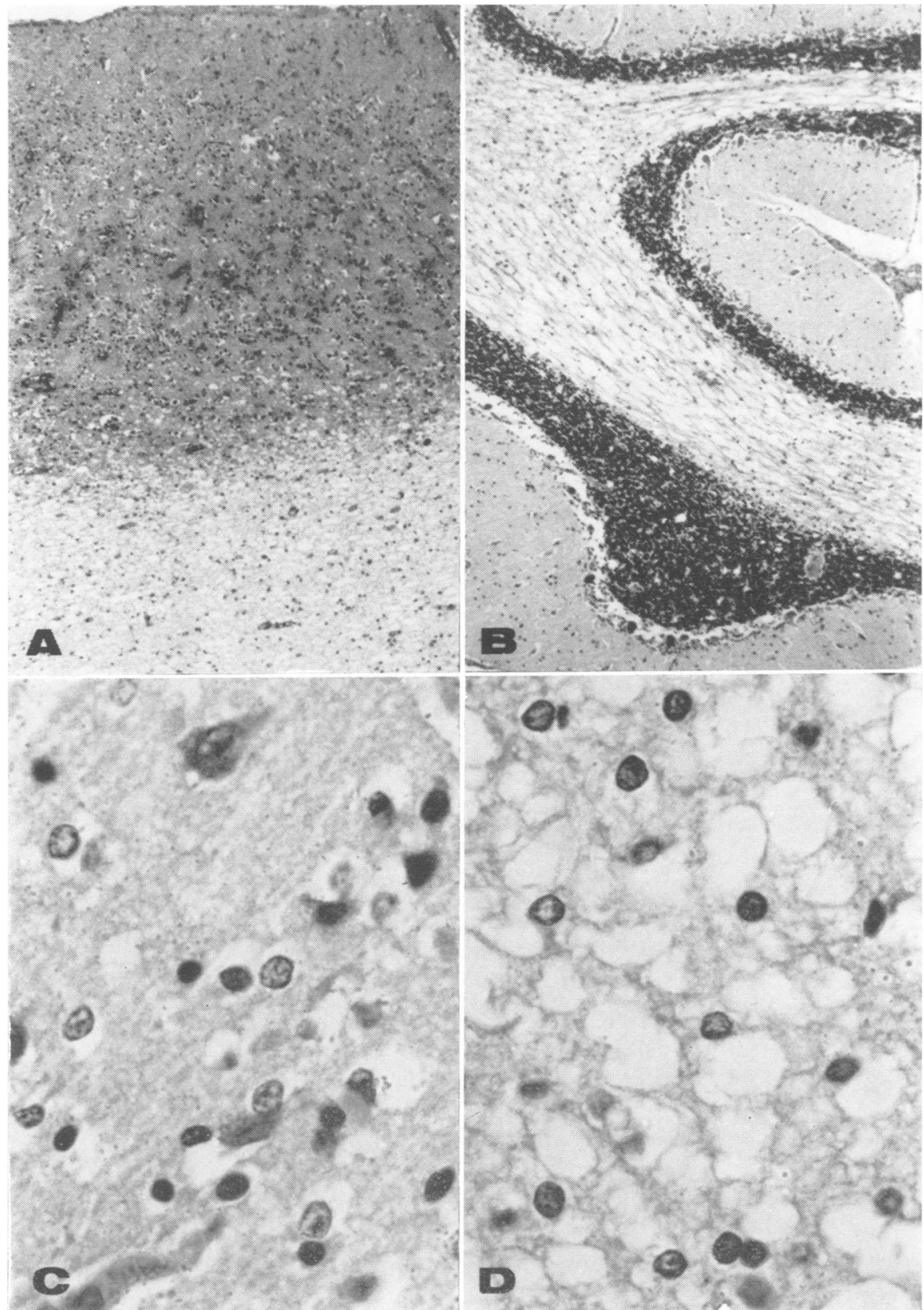

FIG. 2. Changes in the central nervous system (I). A. Cerebral cortex. Note an extensive status spongiosus in the white matter. PAS, paraffin section, $\times 70 . \mathrm{B}$. Cerebellum. Spongy change has extended into intrafolial white matter. Note well-preserved cortical architecture. Haematoxylin-eosin, paraffin section, $\times 70$. C. Higher power view of cerebral cortex. Note large nuclei of Alzheimer type II glias. A relatively intact neurone in the upper centre. Haematoxylin-eosin, $\times 800$. D. Higher power view of the centrum semiovale. Normal looking oligodendroglia are rare. Haematoxylin-eosin, $\times 800$. 


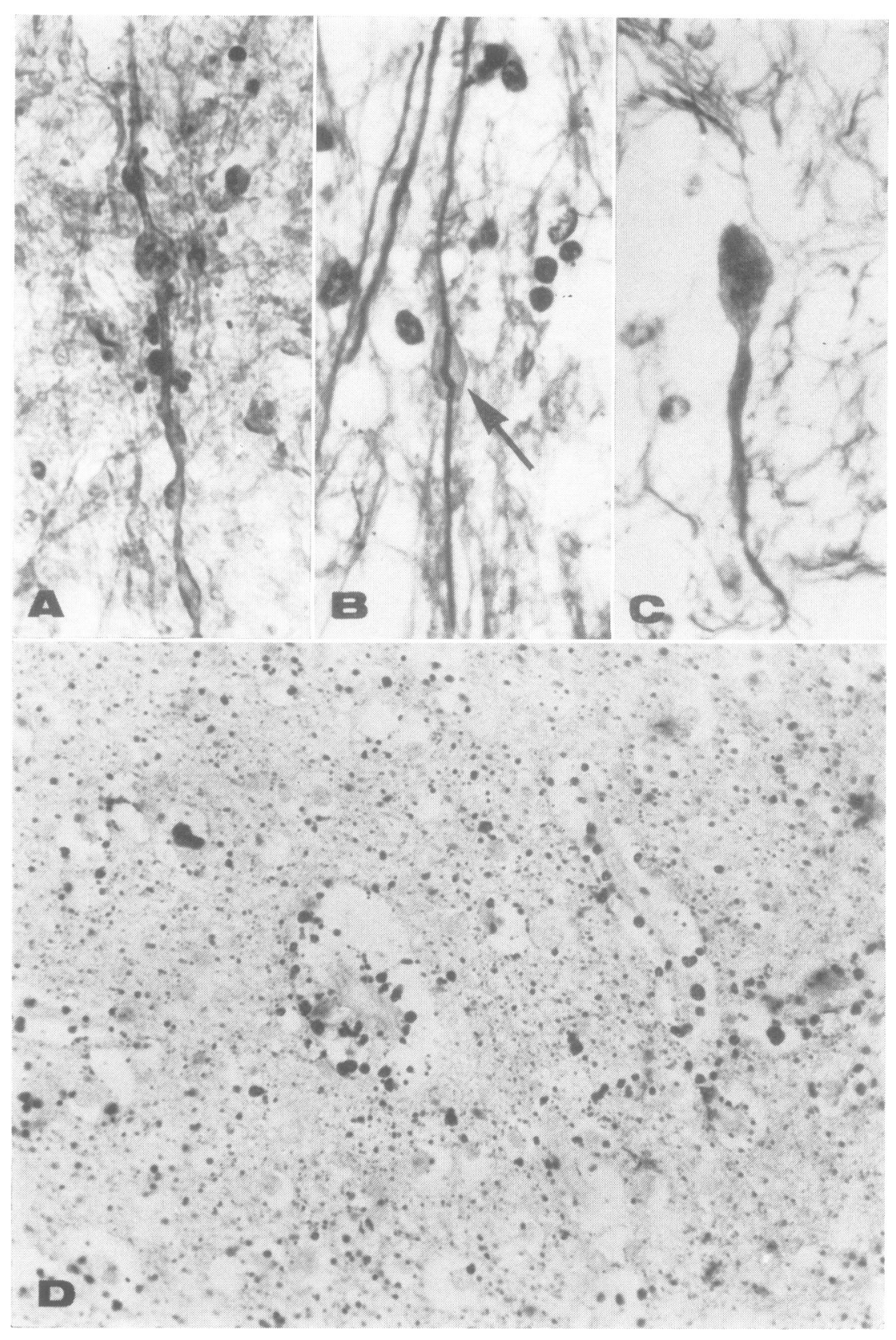

FIG. 3. Changes in the central nervous system (II). A. An irregular moniliform swelling of myelin sheath. Some breakdown products are also seen. Cerebral white matter, Sudan black B, frozen section, $\times 800$. B. Kinking of axon at the site of myelin swelling (arrow). Internal capsule, Bodian-Luxol fast blue, paraffin section, $\times 800$. C. Axonal swelling. This is a rare finding. Pyramidal tract at the level of medulla oblongata, Bodian, paraffin section, $\times 800$. D. Diffuse glycogen deposition in the cerebral cortex. Note the tendency for perivascular arrangement, Best's carmine, paraffin section, $\times 250$. 
affected. Interestingly, here, there were fairly large numbers of interfascicular oligodendroglia. The basal grey structures showed more or less marked spongy change. Their nerve cells were decreased in number and Alzheimer type II astrocytes were found here and there. Severely affected were the thalamus, putamen, and globus pallidus, bilaterally; whereas the caudate nucleus and hypothalamic nuclei were less involved. The scattered islands of fibre bundles in the striatum showed severe spongy change in contrast with the surrounding grey substance. There were only a few oligodendroglia seen in such spongy islands.

The subthalamic nuclei, red nucleus, and substantia nigra showed changes similar to those seen in the basal grey matter and the white matter revealed a severe status spongiosus as noted in the cerebrum.

Nerve cell loss in the pontine nuclei was quite marked, representing the most severely affected grey matter in the brain. The white matter showed variable degrees of status spongiosus. In the myelin preparations, however, some fibre tracts disclosed well-preserved myelin sheaths. These included the lemniscus medialis, tractus longitudinalis medialis,
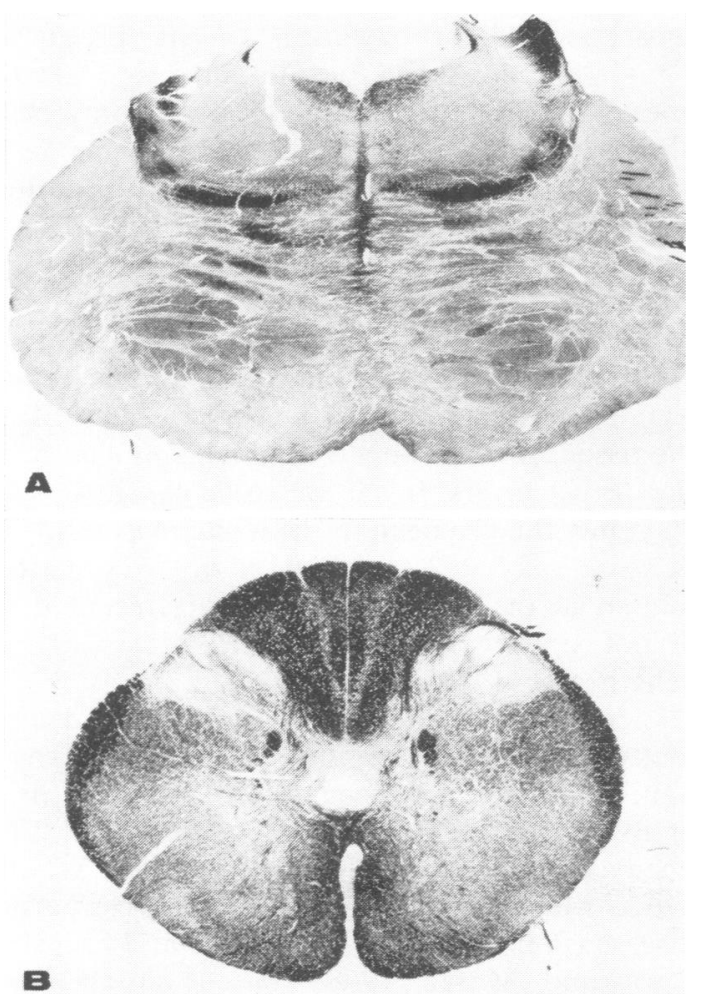

FIG. 4. Systematic preservation of tracts. A. Pons. B. Upper cervical cord. Sugamo method for myelin, frozen sections. brachium conjunctivum, tractus mesencephalicus nervi trigemini, fibrae cruciantes nervi trigemini, and filia radiculata nervi trigemini (Fig. 4a).

The changes observed in the medulla were quite similar to those found elsewhere. The lemniscus medialis was well myelinated at this level also. The inferior olivary nuclei were well preserved, contrasting with the spongy white matter surrounding them.

The cytoarchitecture was essentially normal throughout the cerebellar cortex. The interfolial white matter was involved in variable degrees with spongy change which extended to the intrafolial white matter (Fig. 3B). The deeper white matter, especially around the dentate nucleus, was less affected. The neurones of the dentate nuclei were decreased in number, having a moderately spongy background. The remaining neurones were all shrunken with scanty eosinophilic cytoplasm. Numerous Alzheimer type II astrocytes were found in the dentate nuclei.

The neurones of the grey matter of the spinal cord were well preserved throughout, although their background was variably spongy. While the white matter was involved in a manner similar to that seen elsewhere, there definitely were preserved fibre tracts at multiple levels. The dorsal columns were almost normally myelinated, having a very minimal spongy appearance. The tractus spinocerebellaris dorsalis was also well preserved bilaterally (Fig. 4B). The dorsal as well as ventral roots showed no abnormalities.

The peripheral nerves and cauda equina roots were all normal.

In addition to the above described histological features there was the striking finding of glycogen, demonstrated by PAS reaction and Best carmine stain and confirmed by saliva digestion, diffusely distributed throughout the central nervous system, mainly in the grey matter with frequent perivascular accumulation (Fig. 3D). The glycogen deposits were located chiefly in the neuropil, but occasionally were found in neuronal as well as glial perikarya. In the spongy white matter, the glycogen granules were much less dense and were smaller in size than those in the grey matter, and scattered in the remaining neuropil. Interestingly, the better preserved tracts contained lesser amounts of glycogen than the more severely affected white matter.

CHEMICAL ANALYSIS Fresh tissue from some organs was available for chemical analysis. The pertinent results are shown in Table 2 . Unfortunately, only formalin fixed material was available for detailed lipid analysis of the brain. Since the tissue had been left in the fixative for more than a month, the significance of the results is questionable and no detailed figures are presented; however, there was evidence to suggest that the myelin lipids were drastically re- 
TABLE 2

CHEMICAL ANALYSIS

\begin{tabular}{lccccc}
\hline & \multirow{2}{*}{ Liver } & Kidney & Serum & \multicolumn{2}{c}{ Cerebrum } \\
\cline { 4 - 6 } & & & & White & Grey \\
\hline Total lipids (\%) & 17.0 & 9.5 & 1.26 & $2 \cdot 1-3.4$ & - \\
Phospholipid (mg \%) & 2.89 & 2.59 & 16.9 & - & - \\
Cholesterol (mg \%) & & & & 0.95 & - \\
$\quad$ Total & 1850 & 500 & 675 & 0.95 & - \\
$\quad$ Free & 1475 & 275 & 295 & 0.87 & - \\
$\quad$ Ester & 375 & 225 & 380 & 0.08 & - \\
Glycogen (\%) & 1.21 & 0.3 & - & - & - \\
Water (\%) & - & - & - & 92.0 & 84.4 \\
\hline
\end{tabular}

duced in quantity and that there was no apparent accumulation of abnormal lipids.

\section{DISCUSSION}

The initial clinical impression of the case reported herein was that of von Gierke's disease (glycogenosis type I); however, on the basis of subsequent liver biopsies, which revealed the stored material to be predominantly fat rather than glycogen, the possibility that this case represented an example of 'congenital hypertrophic steatosis of the liver-Debré' was considered.

'Congenital hypertrophic steatosis of the liver', an equivocal entity, is almost identical with von Gierke's disease in terms of clinical symptomatology. The differential diagnosis between the two is, according to van Creveld (1939) and Kleinbaum (1957), totally dependent upon the histological examination of the liver - that is, upon the predominant material stored in the organ (fat-steatosis; glycogen-von Gierke). However, it is not unusual to find an accumulation of fat in the liver in von Gierke's disease (Koch, 1954) and since an abnormal accumulation of fat in the hepatic parenchyma is considered to be the most common, non-specific reaction of the liver to various pathological conditions (Lombardi, 1966), the existence of 'congenital hypertrophic steatosis of the liver' as a clinicopathological entity is questionable. Furthermore, since Cori and Cori (1952) discovered G6Pase deficiency in von Gierke's disease, a biochemical criterion for the disease has been established and on this basis several other types of glycogenoses have been elucidated.

In the present case, a biochemical analysis, including manometric and isotopic studies, was carried out on material obtained at liver biopsy at the age of 9 months, revealing, in addition to a decreased activity of G6Pase-in much the same manner as seen in von Gierke's disease-a markedly elevated activity of G6PDase, which is unusually decreased in cases of von Gierke's $Z$ disease (Weber and Harpur, 1960). These bio- $\frac{\subseteq}{\overline{0}}$ chemical studies have been published previously by Tada et al. (1962). They considered that this marked elevation of G6PDase activity 0 might be the point of delineation between 'congenital hypertrophic steatosis of the liver' and $\frac{\overline{0}}{\mathrm{a}}$ von Gierke's disease; however, this requires further elucidation as the post-mortem examination disclosed glycogen in various organs.

One of the unique features of the present case is the finding of extensive status spongiosus with $\frac{\bar{D}}{\overline{0}}$ an abnormal deposition of glycogen in the $\frac{\vec{\sigma}}{\vec{\alpha}}$ central nervous system. Feigin and his colleagues (Feigin and Budzilovich, 1966; Feigin, Pena, and $\infty$ Budzilovich, 1968) have indicated that spongy $\vec{\circ}$ change in the central nervous system (CNS) $\overrightarrow{.}$ could result from the evolution of gaseous carbon ${ }^{\circ}$ dioxide in the tissue, preterminally or shortly after death, and that this carbon dioxide is? formed by the breakdown of glycogen pre- $w$ sumably deposited in the affected tissue as a $\overrightarrow{-}$ consequence of the underlying disease state wi subsequent decarboxylation of its products Thus, they considered that the status spongioswos does not reflect the pathological anatomy of disease process present in life and may not be 8 valid basis for delineating a nosological entit. The mechanism they propose might have played $\overrightarrow{0}$ a role in the development of the extensive spongy change of the white matter in the present case, because of the abnormal glycogen deposition. 웅 However, the grey matter in the present case, where a large amount of glycogen remained in the tissue, showed only a minimal sponginess in $\frac{}{\circ}$ the deeper layers. It has yet to be clarified as to $\overrightarrow{\vec{F}}$ why only the glycogen in the white matter might 3 be decarboxylated and that in the grey matter remain in the tissue. Furthermore, recent data? do not support Feigin's hypothesis (Jellinger and Seitelberger, 1970).

Increased water and reduced myelin lipid con- $\frac{0}{3}$ tent were found in the brain in the present case. Similar findings have been noted not only in cases of B-BSD, but also in other conditions such as phenylketonuria (Crome, Tymms, and Woolf, 1962; Menkes, 1966) and maple syrup urine disease (Prensky and Moser, 1966; and Prensky, Carr, and Moser, 1968). Based on chemicalos analysis, Kamoshita, Rapin, Suzaki, and Suzaki ${ }^{\circ}$ (1968) considered B-BSD to be primarily $\mathrm{a}_{\mathrm{E}}^{N}$ disease of chronic oedema, with the myelin loss being secondary to water accumulation. Eleceo 
tronmicroscopically, the location of such abnormal accumulation of water has been determined as being interlamellar - that is, within the myelin sheath in brain biopsy of B-BSD (Adachi, Wallace, Schneck, and Volk, 1966; Gambetti, Mellman, and Gonatas, 1969). However, in the present case the presence of oedema alone can not explain the whole pathological picture of the brain, especially the systematic preservation of certain fibre tracts.

The fibre tracts preserved in our case-that is, medial lemniscus, medial longitudinal tracts in the brain-stem, superior cerebellar peduncle, dorsal column and spinocerebellar tracts in the spinal cord, etc.--are those known to be myelinated in the earlier stages of development, approximately from the end of foetal life through early postnatal life (Langworthy, 1933; Yakovlev and Lecours, 1967; Rorke and Riggs, 1969). In other words, the spongy change and associated myelin defect were much more severe in those tracts which are normally myelinated later in development. Preservation of such fibre tracts has been described in cases of B-BSD by van Bogaert and Bertrand themselves (1967). It has been noted also in some cases of the aminoacidurias (Alvord et al., 1950; Silberman et al., 1961). Furthermore, in the case of Solitare et al., (1969), a defect in myelination was noted, but was seen in non-spongy regions as well. In such instances, mechanisms other than oedema are required to account for such faulty myelination. It seems more likely that the oedema is a consequent or concomitant phenomenon, and that while the responsible factor for the spongy change is unknown, a basic metabolic derangement, which apparently also results in an arrest of myelination at certain stages of development, is the primary factor and remains to be elucidated.

It is well known that myelin sphingolipids contain long-chain fatty acids and that the length of fatty acid chain of cerebrosides and sulphatides increases during maturation (O'Brien, 1964; O'Brien and Simpson, 1965; StällbergStenhagen and Svennerholm, 1965; Kishimoto and Radin, 1966; Pilz, 1968). It is quite possible that high energy is required for the synthesis of such long-chain fatty acids (from $\mathrm{C}_{16}$ or $\mathrm{C}_{18}$ to $\mathrm{C}_{22}$ or $\mathrm{C}_{24}$ ), although the exact mechanism is still not fully understood. According to Richter (1955), the energy supply of the foetal brain depends mostly upon glycolysis, whereas during postnatal life it depends upon the cytochrome oxidase system along with the development of mitochondria. Assuming that there is a defect in the cytochrome oxidase system in the brain, or that there is a metabolic error which results in suppression or malfunction of such system, the energy supply of the brain presumably would be forced to depend upon glycolysis, which might not be sufficient for myelination of the later developing tracts of the brain, whereas the primitive part would be completed. Such defects in myelination are known to occur as a result of suppression of the cytochrome oxidase system in the disease of young lambs known as swayback (Barlow, Purves, Butler, and Macintyre, 1960; Howell, Davison, and Oxberry, 1964). With regard to phenylketonuria, several investigators have suggested that there may be a disturbance of the intracerebral elongation process of longchain fatty acids (Foote, Allen, and Agranoff, 1965; Gerstl, Malamud, Eng, and Hayman, 1967; Cumings, Grundt, and Yanagihara, 1968). In experimental conditions, phenylpyruvate has been shown to have an inhibitory effect on oxygen consumption by whole homogenate or slices of rat brain (Howell and Lee, 1963; Itoh, 1965), as well as by a mitochondrial fraction isolated from the cerebral cortex of immature rats (Gallagher, 1969). In cases of B-BSD, abnormal mitochondria have been found in the glial cells of the white matter by electronmicroscopic studies of brain biopsies (Adachi, et al., 1966; Gambetti et al., 1969). ATPase deficiency also has been noted in such abnormal mitochondria (Adachi et al., 1966; Johnson, 1970). Since a considerable portion of the energy produced by mitochondrial respiration is coupled to the so-called ionic pump-that is, $\mathrm{Na}^{+}-\mathrm{K}^{+}$dependent ATPase (Whittam and Blond, 1964) which regulates the permeability of the plasma membrane to ion and water (Skou, 1965; van Harreveld, 1968) - it has been suggested that, if the mitochondria fail in their role in energy supply, a derangement of the ionic pump mechanism could occur with resulting accumulation of water, which would cause status spongiosus in the tissue (Jellinger and Seitelberger, 1970). One may consider, therefore, that the most crucial biochemical disturbance in the spongy degenerations of the white matter lie in the energy supply system-that is, mitochondrial system-rather than in the myelin lipid metabolism itself.

Of the six types of glycogenoses as presently determined, none, to the best of our knowledge, has been reported to develop diffuse spongy 
change of the central white matter. Among the cases of B-BSD, reported in the literature, there are several cases in which fatty change was observed in the liver (see van Bogaert and Bertrand, 1967). However, in these instances, hepatomegaly was not a presenting feature and the histological changes in the liver were regarded as a non-specific reaction of the organ. In the present case, there was a marked hepatomegaly due to abnormal accumulation of fat and glycogen as well as glycogen storage in the myocardium. The uncommon association of such visceral changes with the extensive status spongiosus and glycogen deposition in the CNS distinguishes our case from other related cases. Thus, the question arises as to whether the thesaurismotic changes and the spongy degeneration are merely a coincidental association, or are, in fact, a manifestation of a single disorder. The combination of spongy change in grey and/ or white matter and diffuse hypertrophy of astrocytes with the appearance of Alzheimer type II (and type I) cells has been observed in various liver diseases (see Jellinger and Seitelberger, 1970). In these cases, the CNS lesions usually are regarded as secondary to the liver damage with associated hepatic dysfunction and such are considered as hepatic encephalopathies. In animal experimentation the simultaneous occurrence of spongy change in the CNS and hepatic lesions has been produced by Cuprizone (Suzuki and Kikkawa, 1969). In the present case, on the other hand, the enzymatic studies revealed that there were (1) decreased activity of G6Pase, (2) increased activity of G6PDase and (3) elevated lipogenesis (Tada et al., 1962). According to Dawes and Shelley (1968), the activity of G6Pase is very low or non-existent in the foetal liver and increases after birth, whereas that of G6PDase is very high in the foetal liver and then gradually decreases with postnatal development. Lipogenesis is also very active in the foetal liver. Accordingly, the liver of the present case may be considered to have an enzymatic pattern compatible with that found in the late foetal liver. Thus, generally speaking, the changes in the liver and those of the central nervous system could be regarded as being analogous in that they displayed patterns normally found in late foetal life. Although the aetiology and pathogenesis of the disease remain obscure, one may consider the condition seen in the present case as representing a failure of metabolic adaptation to postnatal life, thereby resulting in an arrest of certain structures at a stage of late foetal life, associated with an excessive accumulation of fat $z$ and glycogen in the involved organs.

\section{REFERENCES}

Adachi, M., Wallace, B. J., Schneck, L., and Volk, B. W. (1966). Fine structure of spongy degeneration of the central $\stackrel{\varsigma}{\square}$ nervous system (van Bogaert and Bertrand type). Journal $\overline{\bar{v}}$ of Neuropathology and Experimental Neurology, 25, 598616.

Alvord, E. C. jr., Stevenson, L. D., Vogel, F. S., and Engle, $\overrightarrow{\vec{Z}}$ R. L. jr. (1950). Neuropathological findings in phenyl- $\mathcal{O}$ pyruvic oligophrenia (phenyl-ketonuria). Journal of 0 Neuropathology and Experimental Neurology, 9, 298-310.

Barlow, R. M., Purves, D., Butler, E. J., and Macintyre, I. J. $\frac{\bar{\sigma}}{\omega}$ (1960). Swayback in South-East Scotland. II. Clinical, $\vec{乛}$ pathological and biochemical aspects. Journal of Com- $₫$ parative Pathology, 70, 411-428.

Bogaert, L. van, and Bertrand, I. (1967). Spongy Degenera- OS tion of the Brain in Infancy. North Holland: Amsterdam. $\vec{\circ}$

Chou, S.-M., and Waisman, H. A. (1965). Spongy degeneration of the central nervous system. Case of homocystinuria. Archives of Pathology, 79, 357-363.

Cori, G. T., and Cori, C. F. (1952). Glucose-6-phosphatase of the liver in glycogen storage disease. Journal of Biological Chemistry, 199. 661-667.

Creveld, S. van (1939). Glycogen disease. Medicine, 18, 1-128. w Crome, L., Tymms, V., and Woolf, L. I. (1962). A chemicalinvestigation of the defects of myelination in phenylketonuria.Journal of Neurology, Neurosurgery, and Psychiatie, 25, 143-148.

Cumings, J. N., Grundt, I. K., and Yanagihara, T. (196\$. Lipid changes in the brain in phenylketonuria. Journal of 7 Neurology, Neurosurgery, and Psychiatry, 31, 334-337. 앙

Dawes, G. S., and Shelley, H. J. (1968). Physiological aspects of carbohydrate metabolism in the foetus and newborn. 9 Carbohydrate Metabolism and its Disorders, pp. 87-18 Edited by F. Dickens, P. J. Randle, and W. J. Whelen, Vol. 2, Academic Press: London.

Donohue, W. L. (1967). Lesions in the central nervous! system associated with inborn errors of amino acid metabolism. Acta Paediatrica Scandinavica, 56, 116-117.

Feigin, I., and Budzilovich, G. (1966). The spongy state: a form due to the agonal or postmortem evolution of gaseous carbon dioxide from glycogen. Acta Neuropathologica, 7. 136-148.

Feigin, I., Pena, C. E., and Budzilovich, G. (1968). The infantile spongy degenerations. Neurology (Minneap.), 18, $\overrightarrow{\bar{\sigma}}$ 153-166.

Foote, J. L., Allen, R. J., and Agranoff, B. W. (1965). Fatty acids in esters and cerebrosides of human brain in phenyl ketonuria. Journal of Lipid Research, 6, 518-524.

Gallagher, B. B. (1969). The effect of phenylpyruvate on oxidative-phosphorylation in brain mitochondria. Journab of Neurochemistry, 16, 1071-1076.

Gambetti, P., Mellman, W. J., and Gonatas, N. K. (1969)음 Familial spongy degeneration of the central nervous system (Van Bogaert-Bertrand disease). An ultrastructura $B$ study. Acta Neuropathologica, 12, 103-115.

Gerstl, B., Malamud, N., Eng, L. F., and Hayman, R. B. (1967). Lipid alterations in human brains in phenylo ketonuria. Neurology (Minneapolis), 17, 51-57.

Harreveld, A. van (1968). Brain Tissue Electrolytes. Buttere worths: London.

Howell, J. McC., Davison, A. N., and Oxberry, J. (1964) N Biochemical and neuropathological changes in swayback? Research in Veterinary Science, 2, 376-384.

Howell, R. K., and Lee, M. (1963). Influence of alphar ketoacids on the respiration of brain in vitro. Proceeding 5 w of the Society for Experimental Biology and Medicine, 113 660-663. 
Itoh, T. (1965). Effects of sodium phenylpyruvate on amino acid formation in brain. Canadian Journal of Biochemistry, 43, 835-840.

Jellinger, K., and Seitelberger, F. (1970). Spongy degeneration of the central nervous system in infancy. Current Topics in Pathoiogy, 53, 90-160.

Johnson, A. B. (1970). Deficiency of ATPase-positive astrocytic processes in spongy degeneration of the nervous system (Canavan's disease). Journal of Neuropathology, and Experimental Neurology, 29, 136.

Kamoshita, S., Rapin, I., Suzuki, K., and Suzuki, K. (1968). Spongy degeneration of the brain. A chemical study of two cases including isolation and characterization of myelin. Neurology (Minneapolis), 18, 975-985.

Kishimoto, Y., and Radin, N. S. (1966). Metabolism of brain glycolipid fatty acids. Lipids, 1, 47-61.

Kleinbaum, H. (1957). Über Fettspeicherleber-Krankheit. Archiv für Kinderheilkunde, 155, 55-62.

Koch, R. (1954). Die gleichzeitige Speicherung von Fett und Glykogen in der Leber. (Hépatomegalie polycorique Debré). Monatsschrift fïr Kunderheilkunde, 102, 9-13.

Langworthy, O. R. (1933). Development of behaviour patterns and myelinization of the nervous system in the human fetus and infant. Contributions to Embryology, 24, no. $139,1-57$.

Lombardi, B. (1966). Considerations on the pathogenesis of fatty liver. Laboratory Investigation, 15, 1-20.

Menkes, J. H. (1966). Cerebral lipids in phenylketonuria. Pediatrics, 37, 967-978.

O'Brien, J. S. (1964). A molecular defect of myelination. Biochemical and Biophysical Research Communications, 15, 484-490.

O'Brien, J. S., and Sampson, E. L. (1965). Fatty acid and fatty aldehyde composition of the major brain lipids in normal human grey matter, white matter, and myelin. Journal of Lipid Research, 6, 545-551.

Pilz, H. (1968). Dünnschichtchromatographische Lipoidstudien vom normalen Hirngewebe und Myelin des Menschen. Deutsche Zeitschrift fïr Nervenheilkunde, 194, 150-166.

Prensky, A. L., and Moser, H. W. (1966). Brain lipids, proteolipids, and free amino acids in maple syrup urine disease. Journal of Neurochemistry, 13, 863-874.

Prensky, A. L., Carr, S., and Moser, H. W. (1968). Development of myelin in inherited disorders of amino acid metabolism. A biochemical investigation. Archives of Neurology, 19, 552-558.

Richter, D. (1955). The metabolism of the developing brain.
In Biochemistry of the Developing Nervous System, Proceedings of the First International Neurochemical Symposium, Oxford, 1954, pp. 225-250. Edited by H. Waelsch. Academic Press: New York.

Rorke, L. B., and Riggs, H. E. (1969). Myelination of the Brain in the Newborn. Lippincott: Philadelphia.

Rushton, D. I. (1968). Spongy degeneration of the white matter of the central nervous system associated with hyperglycinuria. Journal of Clinical Pathologv, 21, 456-462.

Ställberg-Stenhagen, S., and Svennerholm, L. (1965). Fatty acid composition of human brain sphingomyelins. Normal variation with age and changes during myelin disorders. Journal of Lipid Research, 6, 146-155.

Seitelberger, F. (1967). The problem of status spongiosus. In Brain Edema, Proceedings of the Symposium, 1965, Vienna, pp. 152-169. Edited by I. Klatzo, and F. Seitelberger. Springer: New York.

Silberman, J., Dancis, J., and Feigin, I. (1961). Neuropathological observations in maple syrup urine disease. Branched-chain ketoaciduria. Archives of Neurology, 5, 351-363.

Skou, J. C. (1965). Enzymatic basis for active transport of $\mathrm{Na}^{+}$and $\mathrm{K}^{+}$across cell membrane. Physiological Review's, 45, 596-617.

Solitare, G. B., Shih, V. E., Nelligan, D. J., and Dolan, T. F. Jr. (1969). Argininosuccinic aciduria: clinical, biochemical, anatomical, and neuropathological observations. Journal of Mental Deficiency Research, 13, 153-170.

Suzuki, K., and Kikkawa, Y. (1969). Status spongiosus of CNS and hepatic changes induced by Cuprizone (biscyclohexanone oxalyldihydrazone). American Journal of Pathology, 54, 307-317.

Tada, K., Katsushima, N., Hirono, H., and Arakawa, T. (1962). Congenital steatosis of the liver, biochemical approach to its pathogenesis. Tohoku Journal of Experimental Medicine, 77, 317-333.

Weber, G., and Harpur, E. R. (1960). Liver enzymes in glycogen storage disease. Metabolism, 9, 880-883.

Whittam, R., and Blond, D. M. (1964). Respiratory control by adenosine triphosphatase involved in active transport in brain cortex. Biochemical Journal, 92, 147-158.

Yakovlev, P. I., and Lecours, A.-R. (1967). The myelogenetic cycles of regional maturation of the brain. In Regional Development of the Brain in Early Life. A Symposium organized by The Council for International Organizations of Medical Sciences and by the Délégation à la Recherche Scientifique et Technique, pp. 3-65. Edited by A. Minkowski. Blackwell Scientific Publications: Oxford. 